\title{
Worker reproduction in ants - a genetic analysis
}

\author{
LAURA WALIN*†, LISELOTTE SUNDSTRÖM†§, PERTTU SEPPÄ††ף \& \\ RAINER ROSENGREN $\dagger$ \\ $\dagger$ Department of Ecology and Systematics, University of Helsinki, PO Box 17, FIN-00014 University of Helsinki, \\ Finland, †Department of Biosciences, University of Helsinki, Finland and §Department of Genetics and Ecology, \\ Aarhus University, DK-8000 Aarhus C, Denmark
}

\begin{abstract}
Workers of social insects may enhance their inclusive fitness by laying unfertilized eggs that develop into males. In particular, workers may gain from rearing worker-produced males if their average relatedness to them exceeds their relatedness to queen-produced males. These relatedness values depend both on the queen mating frequency and on the number and relatedness of nestmate queens. We examined the occurrence of worker reproduction in field colonies of four ant species of the genera Formica and Myrmica. Based on relatedness arguments alone, worker reproduction was expected in all species because of low queen mating frequency, or low effective queen numbers. Nevertheless, genotype matching of workers and males showed that worker reproduction was absent or rare in two of the three Formica species studied here. In M. ruginodis, queens may have been the sisters of the workers in many cases, which means that workers of this species may regularly rear nephews. In the three species in which worker reproduction was not found, workers bias colony sex ratios to enhance their inclusive fitness. We therefore hypothesize that sex ratio biasing and male production may be mutually exclusive strategies for workers.
\end{abstract}

Keywords: ants, kin selection, mating frequency, relatedness, worker reproduction.

\section{Introduction}

Workers in many eusocial Hymenoptera have functional ovaries and are able to lay haploid eggs that develop into males (Bourke \& Franks, 1995). Worker reproduction, however, creates a conflict between queen(s) and workers. A queen is more related to her sons $(r=0.5)$ than to her grandsons $(r=0.25)$, whereas workers may enhance their inclusive fitness by rearing sons and/or males laid by other workers. A worker always benefits from producing her own sons, but the relatedness between a worker and the males produced by her nestmate workers depends on the colony kin structure. The relatedness is at a maximum, 0.375, when the queen is singly mated, and decreases if the queen is multiply mated, or if there are several related reproductive queens in the colony (Ratnieks, 1988; Pamilo, 1991b). Once the relatedness between workers and worker-produced males drops below that between workers and queen-produced males,

*Correspondence. E-mail: laura.walin@helsinki.fi

IPresent address: Department of Genetics, Uppsala University, Sweden. workers are expected to prevent each other from reproducing. Such 'worker policing' may be expected even at a considerable cost to the colony (Ratnieks, 1988). Hence, based on kinship arguments, worker reproduction is expected when the population-wide effective queen mating frequency is below two, or in the case of related nestmate queens if

$n_{\mathrm{q}}<1+1 / r_{\mathrm{q}}$,

where $n_{\mathrm{q}}=$ effective number of queens and $r_{\mathrm{q}}=$ relatedness among coexisting queens (Pamilo, 1991b). These arguments apply when factors other than relatedness are assumed to have no impact.

Several authors have suggested that worker reproduction might be fairly common in Formica and Myrmica (Brian, 1953, 1969; Smeeton, 1981; Pamilo, 1982; Nonacs, 1992). In Formica Gösswald (1989, 1990) observed worker egg-laying in the absence of the queen, and dequeened $F$. exsecta colonies produced males only (Pamilo, 1991a). Similarly Myrmica workers produced males in queenless laboratory colonies (Brian, 1953; Mamsch \& Bier, 1966; Brian, 1969), but worker reproduction was absent in queenright colonies (Mamsch \& Bier, 
1966). There is some intriguing evidence, based on hypervariable microsatellite markers, that in nearctic Myrmica tahoensis males may be produced by workers (Evans, 1993). By contrast, in the genus Leptothorax worker reproduction seems to be low or absent in queenright colonies (Heinze et al., 1997).

Most studies on worker reproduction in Formica and Myrmica, however, are not based on genetic data (Bourke \& Franks, 1995), and it remains unclear whether workers in these two ant genera regularly produce males in natural queenright colonies.

Inclusive fitness benefits of male production by workers are tightly linked to sex ratio specialization of the colonies. The worker optimum in colonies with one singly mated queen is to rear females only (Boomsma \& Grafen, 1990, 1991), but these are also the colonies in which male production by workers is most strongly favoured (Ratnieks, 1988; Pamilo, 1991b). Hence, sex ratio biasing and worker reproduction may be mutually exclusive strategies for the workers. In our study species, worker-controlled sex ratio specialization has been demonstrated in $F$. truncorum, F. exsecta and M. ruginodis (Sundström, 1994; Sundström et al., 1996; Walin \& Seppä, unpubl. obs.) but not in F. rufa (Walin et al., unpubl. obs.), and will not be analysed further here.

In this study we use genetic markers to examine the occurrence of worker reproduction in four species of the genera Formica and Myrmica. The species chosen are of two types: species with singlequeened colonies in which there is variation in queen mating frequency $(F$. truncorum, $F$. exsecta and F. rufa; Sundström, 1994, 1995; Sundström et al., 1996), and species in which the queen number varies but queens are singly mated (M. ruginodis; Seppä, 1994). In a previous study, all males were shown to be queen-derived in queenright colonies of $F$. exsecta (Sundström et al., 1996). This was based only on genotype distributions, and we include the species here for a more thorough analysis. Based on inclusive fitness arguments alone, worker reproduction is expected in Formica if the population-wide queen mating frequency is below two, and in M. ruginodis if the effective queen number (according to eqn 1 ) is low enough.

\section{Materials and methods}

\section{Genetic analysis}

We collected workers and males from $79 \mathrm{~F}$. rufa colonies in 1994 in the Inkoo archipelago of southern Finland (64 colonies from different islands,
15 from the mainland). Five polymorphic allozyme loci were screened (Appendix) using the protocols given in Seppä (1996). The genetic data on F. truncorum, $F$. exsecta and $M$. ruginodis have been published elsewhere (see Appendix). The F. truncorum data have been supplemented with new colonies. Sampling in all species was carried out when males were still at the pupal stage. In $M$. ruginodis entire colonies were excavated.

\section{Effective mating frequencies and paternity bias in Formica}

In Formica, we did not excavate the colonies and collect queens. Instead, we inferred the parental genotypes from the worker genotypes and divided the colonies into those headed by singly, doubly or multiply mated queens. The genotype(s) of the father(s) were deduced assuming the smallest number of matings that explained the worker genotypes. The proportion of workers fathered by each male was then assessed as the frequency of each specific worker genotype attributed to him.

The variance in paternity was calculated correcting for sample size (Pamilo, 1993):

$\Sigma p_{i}^{2}=\left(N \Sigma y_{i}^{2}-1\right) /(N-1)$,

where $y_{i}$ is the proportion of the offspring fathered by the $i$ th male, and $N$ is the number of offspring analysed. The variance in paternity was calculated separately for the doubly and multiply mated classes of colonies.

The population-wide effective mating frequency was estimated from the average relatedness among nestmate workers $\left(M_{\mathrm{e}}\right)$ (Ross, 1993):

$M_{\mathrm{e}}=\left(2 r_{\mathrm{fs}}-0.5-r_{\mathrm{m} 2}\right) /\left(2 r_{\mathrm{s}}-0.5-r_{\mathrm{m} 2}\right)$,

where $r_{\mathrm{fs}}$ is the relatedness among workers that belong to the same patriline, $r_{\mathrm{m} 2}$ is the relatedness among male mates of single queens (assumed to be zero; Seppä, 1994) and $r_{\mathrm{s}}$ is the relatedness among workers.

Furthermore, we determined the efficiency of double and multiple mating from the average paternity variance $\left(M_{\mathrm{p}}\right)$ (Pamilo, 1993):

$M_{\mathrm{p}}=1 / \Sigma p_{i}^{2}$.

\section{The number of queens in $M$. ruginodis colonies}

For $M$. ruginodis we classified the colonies into single-queen and multiple-queen ones according to the observed worker genotypes, and assuming single 
mating by queens (Seppä, 1994). The effective number of queens $\left(n_{\mathrm{q}}\right)$ in the study population (1.7; Walin \& Seppä, unpubl. obs.) was determined according to Ross (1993).

\section{Relatedness and genotype matching of workers and males}

The within-colony relatedness for workers and for males, as well as relatedness between workers and males (given as life-for-life relatedness; see, e.g. Grafen, 1991) were estimated from genotype frequency data using the algorithms of Queller \& Goodnight (1989) and Pamilo (1990a). The expected worker-male relatedness depends on queen number, the relatedness among queens, and the fraction of worker-produced males. The observed values were compared to the expected ones, which were calculated as follows.

All males produced by queens:

expected $r_{\mathrm{w}-\mathrm{m}}=\left[0.25+0.25 \times r_{\mathrm{q}}\left(n_{\mathrm{q}}-1\right)\right] / n_{\mathrm{q}}$.

All males produced by workers:

expected $r_{\mathrm{w}-\mathrm{m}}=\left[0.25(0.5+1 / M)+0.125 \times r_{\mathrm{q}}\left(n_{\mathrm{q}}-1\right)\right] / n_{\mathrm{q}}$,

where $M=$ absolute number of mates of the queen, $r_{\mathrm{q}}=$ relatedness among nestmate queens, $n_{\mathrm{q}}=$ effective number of queens (Pamilo, 1990b).

Worker reproduction may occur, but workerproduced males may not be detected if the genetic resolution is low, or if sample sizes are small. Also, if only a fraction of all males is produced by workers, the expected worker-male relatedness values vary between 0.375 and 0.25 . Given our sample size of 20 males, worker-produced males can be detected with a $95 \%$ probability when their frequency is $25 \%$, if the paternal alleles differ from the maternal ones. Otherwise, the detection probability will be a function of the frequency of workers carrying diagnostic alleles and of the effective sample size. However, if the male mates of queens carry alleles identical to those of the queens, worker- and queen-produced males cannot be distinguished.

Therefore, we also examined the multilocus genotypes of workers and males in all colonies. In $M$. ruginodis queen genotypes were also available. We classified the colonies according to five criteria: (1) worker reproduction can be excluded if all workers are heterozygous at one or more loci, and only one allele is found in males; (2) worker reproduction is unlikely or rare if workers carry at least one allele that is not found in males (assuming that any worker genotype is equally likely to contribute to male production); (3) worker reproduction is likely if all workers are heterozygous at least at one locus, and both alleles are found among the males; (4) worker reproduction is possible if three male genotypes are found and worker genotypes are consistent with one (singly mated) queen; (5) worker reproduction remains unresolved if only homozygous, or both homozygous and heterozygous worker genotypes are found and all worker alleles are present in males. The different possibilities and their probabilities are given in Table 1.

\section{Results}

\section{Formica}

In all Formica species the population-wide effective mating frequency $\left(M_{\mathrm{e}}\right)$ was below two (Table 2). The effective mating frequency $\left(M_{\mathrm{p}}\right)$ was also slightly below two in the doubly mated class of colonies, and between two and three in the multiply mated class of colonies (Table 2). Worker nestmate relatedness $(r)$ was consistent with the expected value of 0.75 in colonies headed by a singly mated queen, and with 0.5 in the multiply mated class (Table 3 ). Similarly, male-male relatedness was generally close to that expected for full brothers (0.5), except in $F$. rufa colonies with multiply mated queens (Table 3 ). The confidence limits showed that worker-male relatedness did not differ from 0.25 in any species (Table 3), which is consistent with the males being queen-produced.

If all males were worker-produced in the singly mated class of colonies, the worker-male relatedness should be 0.375 . The upper $95 \%$ confidence limits overlapped with this in $F$. exsecta and $F$. rufa, but not in $F$. truncorum (Table 3 ). However, the average worker-male relatedness will be between 0.25 and 0.375 if workers produce some of the males. So low frequencies of worker-produced males may remain undetected when only relatedness estimates are used. In colonies headed by doubly mated queens, the worker-male relatedness is expected to be 0.25 , independently of the source of males. Thus, in this class of colonies worker- and queen-produced males cannot be separated using relatedness estimates.

Genotype matching suggested that worker reproduction could be excluded in 33 out of 38 , and 16 


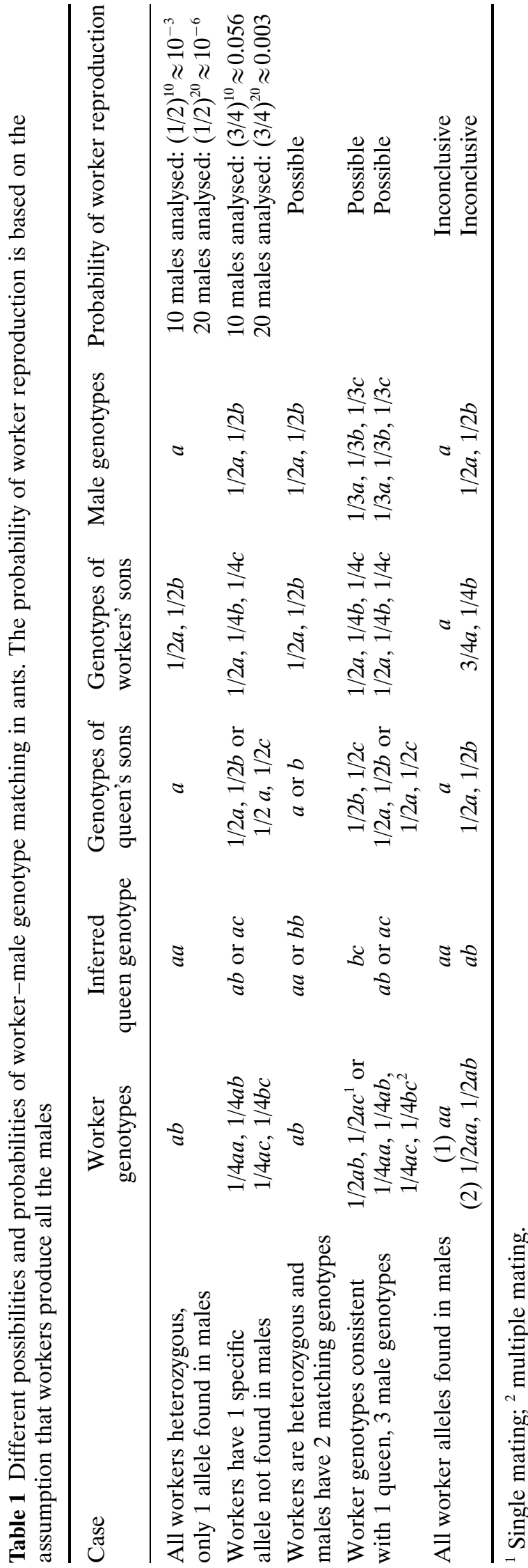

out of 24 colonies of $F$. exsecta and $F$. truncorum, respectively. Despite the reasonably high detection power of our genetic markers, worker reproduction was never classified as possible in these two species (Table 4). By contrast, in $F$. rufa worker reproduction was classified as possible in eight out of 41 colonies, and more often possible than unlikely in colonies with singly mated queens compared to colonies with multiply mated queens (Fisher's exact test $P=0.03$, one-tailed; a one-tailed test was used because worker reproduction may be expected in colonies with singly mated queens but not in those with multiply mated queens, but not the other way around; Ratnieks, 1988). Colonies with singly mated queens were also more frequent than those with multiply mated queens, in the category of inconclusive cases (Fisher's exact test, $P=0.007$, two-tailed). Hence, worker reproduction may have occurred in a number of colonies headed by singly mated queens, although they could not be detected.

\section{Myrmica ruginodis}

The high relatedness $(r=0.84 \pm 0.05)$ among nestmate workers in single-queen colonies of our study population (Table 5) suggests single mating by queens in our study population. The expected worker-male relatedness values (for queen- and worker-produced males, respectively) were calculated with the observed queen relatedness of $r=0.48 \pm 0.10 \quad(N=21$; Walin \& Seppä, unpubl. obs.) (Table 5). From eqn (1) it follows that worker reproduction is expected if the effective number of queens $\left(n_{\mathrm{q}}\right)$ is 3.1 or below. In our study population the effective number of queens was 1.7 (Table 5; Walin \& Seppä, unpubl. obs.).

The population-wide worker-male relatedness was close to the value expected if all males are produced by the queens, but below the value expected if all males are produced by the workers (Table 5). However, the worker-male relatedness of single-queen colonies was very close to the value expected under worker reproduction (Table 5), although not significantly above 0.25 . In the multiple-queen colonies the expected worker-male relatedness values are similar under queen and worker production, so relatedness estimates cannot be used to separate between worker- and queenproduced males.

Based on genotype matching, we found no cases in which worker reproduction was classified as possible, and 18 cases in which worker reproduction was classified as unlikely in $M$. ruginodis (Table 6). One of the nine inconclusive cases was classified as 
Table 2 Effective number of matings $\left(M_{\mathrm{e}}, M_{\mathrm{p}}\right)$ and paternity variance $\left(\Sigma p_{i}^{2}\right)$ in the study species of Formica. $M_{\mathrm{e}}$ is the population-wide effective mating frequency calculated from worker nestmate relatedness, $M_{\mathrm{p}}$ is the effective number of matings calculated from colonywise paternity bias estimates. All values are mean $\pm \mathrm{SD}$

\begin{tabular}{|c|c|c|c|c|c|c|c|c|}
\hline & \multicolumn{2}{|c|}{ All colonies } & \multicolumn{3}{|c|}{ Doubly mated queens } & \multicolumn{3}{|c|}{ Multiply mated queens } \\
\hline & $N$ & $M_{\mathrm{e}}$ & $N$ & $M_{\mathrm{p}}$ & $\Sigma p_{i}^{2}$ & $N$ & $M_{\mathrm{p}}$ & $\Sigma p_{i}^{2}$ \\
\hline F. exsecta $^{1}$ & 56 & 1.35 & 19 & $1.82 \pm 0.38$ & $0.59 \pm 0.15$ & 3 & $2.36 \pm 0.46$ & $0.43 \pm 0.09$ \\
\hline F. rufa & 79 & 1.47 & 24 & $1.82 \pm 0.40$ & $0.59 \pm 0.15$ & 7 & $2.75 \pm 0.75$ & $0.39 \pm 0.11$ \\
\hline F. truncorum $^{2}$ & 30 & 1.43 & 10 & $1.77 \pm 0.14$ & $0.61 \pm 0.07$ & 2 & $1.97 \pm 0.32$ & $0.51 \pm 0.01$ \\
\hline
\end{tabular}

${ }^{1}$ Sundström et al. (1996).

${ }^{2}$ Sundström (unpubl. obs.).

Table 3 Relatedness estimates for Formica studied. All values are mean $\pm 95 \%$ confidence intervals

\begin{tabular}{|c|c|c|c|c|c|c|}
\hline & All colonies & $N$ & Singly mated & $N$ & Multiply mated & $N$ \\
\hline \multicolumn{7}{|c|}{ Worker-worker relatedness } \\
\hline F. exsecta ${ }^{1}$ & $0.62 \pm 0.06$ & 56 & $0.75 \pm 0.06$ & 34 & $0.44 \pm 0.08$ & 22 \\
\hline F. rufa & $0.59 \pm 0.06$ & 79 & $0.68 \pm 0.08$ & 51 & $0.50 \pm 0.14$ & 28 \\
\hline F. truncorum ${ }^{2}$ & $0.60 \pm 0.08$ & 30 & $0.68 \pm 0.12$ & 17 & $0.49 \pm 0.20$ & 13 \\
\hline \multicolumn{7}{|c|}{ Male-male relatedness } \\
\hline F. truncorum & $0.39 \pm 0.12$ & 24 & $0.42 \pm 0.18$ & 12 & $0.35 \pm 0.18$ & 12 \\
\hline \multicolumn{7}{|c|}{ Worker-male relatedness } \\
\hline F. exsecta & $0.29 \pm 0.08$ & 41 & $0.30 \pm 0.10$ & 20 & $0.27 \pm 0.10$ & 21 \\
\hline F. rufa & $0.25 \pm 0.06$ & 41 & $0.31 \pm 0.10$ & 25 & $0.19 \pm 0.10$ & 16 \\
\hline F. truncorum & $0.15 \pm 0.10$ & 24 & $0.16 \pm 0.10$ & 12 & $0.14 \pm 0.18$ & 12 \\
\hline
\end{tabular}

${ }^{1}$ Sundström et al. (1996).

${ }^{2}$ Sundström (1993); Sundström (unpubl. obs.).

Table 4 Colony-specific genotype matching for workers and males in Formica. The observed number of colonies in each category is given with any particular colony entered only once

\begin{tabular}{|c|c|c|c|c|c|c|c|}
\hline & \multicolumn{6}{|c|}{ Queen mating frequency } & \multirow{3}{*}{$\begin{array}{l}\text { Worker } \\
\text { reproduction }\end{array}$} \\
\hline & \multicolumn{2}{|c|}{ F. exsecta } & \multicolumn{2}{|c|}{ F. rufa } & \multicolumn{2}{|c|}{ F. truncorum } & \\
\hline & 1 & $>1$ & 1 & $>1$ & 1 & $>1$ & \\
\hline \multicolumn{8}{|l|}{ All workers heterozygous at least at one locus } \\
\hline At least one worker allele not found in males & - & 5 & - & 6 & - & 6 & Unlikely \\
\hline All worker alleles found in males & 2 & 3 & 14 & 2 & 5 & 3 & Inconclusive \\
\hline Three male genotypes & - & - & 5 & 2 & - & - & Possible \\
\hline One male allele not found in workers & - & - & - & 1 & - & - & Polygyny \\
\hline
\end{tabular}

Note: all orphaned nests are excluded. 
Table 5 Effective queen numbers $\left(n_{\mathrm{q}}\right)$, and relatedness estimates $(r)$ for Myrmica ruginodis. All values are mean $\pm 95 \%$ confidence intervals

\begin{tabular}{lllllll}
\hline & \multicolumn{1}{c}{ All $^{1}$} & $N$ & Single-queen & $N$ & Multiple-queen & $N$ \\
\hline$n_{\mathrm{q}}$ & 1.7 & & 1.0 & & \multicolumn{2}{l}{3.7} \\
$r$ (adult workers) & $0.49 \pm 0.12$ & 35 & $0.84 \pm 0.10$ & 12 & $0.29 \pm 0.12$ & 23 \\
$r$ (males) & $0.46 \pm 0.10$ & 27 & $0.58 \pm 0.18$ & 7 & $0.41 \pm 0.12$ & 20 \\
$r$ (adult workers-to-males) & $0.15 \pm 0.10$ & 27 & $0.35 \pm 0.22$ & 7 & $0.13 \pm 0.06$ & 20 \\
$r$ (worker pupae-to-males) & $0.17 \pm 0.10$ & 26 & $0.33 \pm 0.22$ & 7 & $0.11 \pm 0.08$ & 19 \\
$\quad$ Expected $r$ (workers-to-males) & & & & & & \\
$\quad$ if males are queen-produced & 0.18 & & 0.25 & & 0.21 & \\
$\quad$ if males are worker-produced & 0.24 & 0.375 & & & \\
\hline
\end{tabular}

${ }^{1}$ Walin \& Seppä (unpubl. obs.).

such because only three males were produced. In 12 colonies (three single-queen and nine multiplequeen colonies) the genotypes of queens, adult workers, worker pupae and males strongly suggested queen turnover between the two different cohorts of offspring.

\section{Discussion}

In all our study species the fitness return for workers from rearing worker-produced males exceeds that of rearing queen-produced males, when kinship arguments alone are considered. Nevertheless, any significant amount of worker reproduction seems highly unlikely in F. exsecta, F. truncorum and M. ruginodis, but in F. rufa worker reproduction may occur. We discuss each of the species separately below.

\section{Formica}

In $F$. exsecta the upper $95 \%$ confidence limits of the worker-male relatedness estimate marginally overlapped with that expected, if all males were workerproduced. However, the worker-male relatedness estimates were probably boosted by slight inbreeding $(F=0.13 \pm 0.06)$. The relatedness estimate given for the workers was corrected for inbreeding (Pamilo, 1985), but because males are haploid this inbreeding correction is not applicable for intercaste relatedness estimates. In this species the genetic resolution was

Table 6 Colony-specific genotype matching for queens, workers and males in Myrmica ruginodis. Any particular colony is entered only once

\section{Number of queens}

$1>1$

Worker reproduction

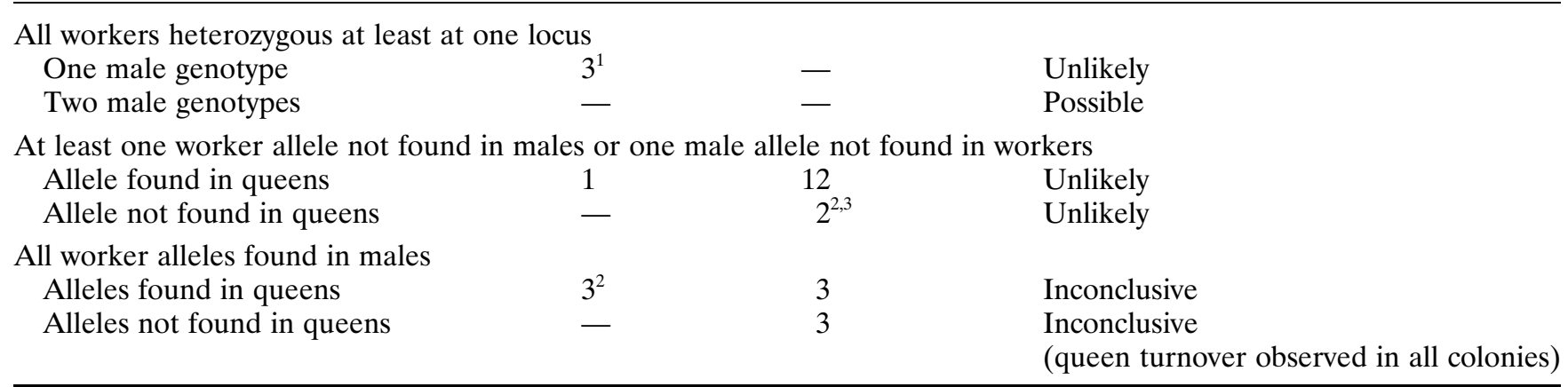

${ }^{1}$ One colony with only five males analysed.

${ }^{2}$ One colony with only three males analysed.

${ }^{3}$ In one colony queen genotype not available.

(C) The Genetical Society of Great Britain, Heredity, 81, 604-612. 
very high, with two microsatellite loci (one with 25 alleles; see Chapuisat, 1996) and three allozyme loci. Consequently, combined with the results from genotype matching, our conclusion is that worker reproduction does not occur, or is very rare, in queenright F. exsecta colonies. Previous studies, however, suggest that workers may produce males in orphaned colonies (Pamilo \& Rosengren, 1983; Pamilo, 1991a; Sundström et al., 1996).

In F. truncorum the worker-male relatedness was consistently below 0.25 , apparently because of a slight heterozygote excess among queens (Sundström, 1993). Genotype matching gave no evidence in favour of worker reproduction, and less than half the cases were inconclusive. Hence, worker reproduction apparently does not occur, or is rare, in queenright colonies.

In $F$. rufa the average worker-male relatedness was close to 0.25 , but that of the singly mated category overlapped with the expected relatedness (0.375) under worker reproduction. In this species inbreeding was insignificant $(F=0.07 \pm 0.05)$, and could not account for the difference in worker-male relatedness between colonies headed by singly mated vs. multiply mated queens (Table 2). Some colonies classified as having one multiply mated queen may, in fact, have had multiple queens, which would result in a low male-male relatedness. This is not a serious problem, however, as the predictions about worker reproduction are similar in both cases (Ratnieks, 1988; Pamilo, 1991b).

In five colonies three male genotypes were found, but worker genotypes were fully consistent with one singly mated queen, suggesting that some males were worker-produced. In addition, workerproduced males were significantly more often considered possible in the singly mated than in the multiply mated class of colonies. Finally, almost $70 \%$ of the cases in which worker reproduction was considered unlikely were in the multiply mated class of colonies. Hence, some males may be produced by workers in colonies with singly mated queens, whereas this seems less likely in colonies headed by multiply mated queens. Such a pattern would be consistent with the worker policing hypothesis (Ratnieks, 1988) and might suggest facultative policing behaviour.

\section{Myrmica ruginodis}

The population-wide worker-male relatedness estimate suggests that males are queen-produced. In the single-queen colonies the worker-male relatedness suggests that the males may be the nephews of the workers, but the genotype matching revealed no possible cases of worker reproduction in either type of colonies. Moreover, given the observed workerworker and queen-queen relatedness, the workermale relatedness in the multiple-queen colonies was lower than expected.

Such a pattern may arise from the complex lifecycles (Elmes, 1991) and rapid queen turnover (Seppä, 1994; Evans, 1996), that characterize Myrmica. Indeed, the genotypes of resident queens, adult workers, worker pupae and males suggested queen turnover in 12 of our 27 colonies. In our study area both sexual and worker brood take one year to mature (pers. obs.). Thus, males and worker pupae share parents, but adult workers in the same colony may represent a different set of parents. Following a continuous process of recruitment of daughters, resident queens may in some cases be the sisters of the adult workers, which could explain both the high worker-worker and worker-male relatedness in the single-queen colonies, and still be consistent with a male-male relatedness of 0.5 . Similarly, queen turnover could cause the low worker-male relatedness in the multiple-queen colonies because some of the queens that laid the males were no longer present in the colony at the time of excavation.

\section{Worker reproduction and sex allocation}

Contrary to the theoretical predictions (Ratnieks, 1988; Pamilo, 1991b), worker reproduction seems to be fairly uncommon in the species studied here. The perspective changes, however, when factors other than kinship are taken into account. For instance, workers may simply respond to the fact that the queen's egglaying capacity exceeds that of the workers.

Another possibility is that facultative sex ratio biasing interferes with worker reproduction. In $F$. exsecta and $F$. truncorum, but not in $F$. rufa, workers eliminate male brood in colonies headed by a singly mated queen (Sundström, 1994; Sundström et al., 1996; Walin et al. unpubl. obs.). Similarly, in $M$. ruginodis workers bias sex ratios according to queen number, producing more female-biased sex ratios in colonies headed by one queen (Walin \& Seppä, unpubl. obs.). These are precisely the classes of colonies where the fitness benefits of worker reproduction are considerable and worker-produced males are most easily identified based on genotype data.

In Formica the inclusive fitness gain from worker reproduction in the class of multiply mated class of 
colonies is small. Given that most males are regularly destroyed in colonies headed by singly mated queens, minor costs associated with male production may under such conditions also prevent worker reproduction from evolving. Such costs may arise if the sex of the brood cannot be assessed early and/or accurately enough, so that queen-laid eggs can be replaced with worker-laid eggs (Nonacs, 1992). The absence of worker reproduction in two of the three Formica species may suggest that the overall fitness return from producing males is lower than that from biasing sex ratios, and that workers trade off maleproduction against sex ratio biasing. In this context it is very suggestive that any evidence in favour of worker reproduction comes from the only species in which facultative sex ratio biasing in response to queen mating frequency does not seem to occur.

In $M$. ruginodis workers may in principle gain increased fitness returns both through facultative sex ratio biasing and by rearing nephews. In multiplequeen colonies workers are indifferent with respect to the origin of males, suggesting that selection for worker reproduction acts mainly through benefits to workers in single-queen colonies. By contrast, in single-queen colonies the workers would be rearing their nephews if the colony queen is their sister. Following queen turnover and recruitment of daughters as new queens, colony queens alternate between being the sister and the mother of the adult workers. In addition, colonies may cycle between a single-queen and multiple-queen state (Elmes \& Keller, 1993). As a result, worker reproduction would not be consistently favoured by selection, if facultative sex ratio biasing yields higher fitness returns, but workers may gain a transient advantage of rearing nephews if the colony queen is their sister.

\section{Acknow ledgements}

We thank Andrew Bourke, Laurent Keller, Jan Lindström, Francis Ratnieks and two anonymous referees for useful comments on earlier drafts of this manuscript. This study was funded by the Academy of Finland (L.W., L.S.), E. J. Sariola Foundation (L.W.), the Danish Natural Sciences Research Council (L.S.) and the Emil Aaltonen Foundation (P.S.).

\section{References}

AYALA, F. J., VALENTINE, J. W., BARR, C. G. AND ZUMWALT, G. S. 1974. Genetic variability in a temperate intertidal phoronid, Phoronopsis viridis. Biochem. Genet., 11, 413-427.

BOOMSMA, J. J. AND GRAFEN, A. 1990. Intraspecific variation in ant sex ratios and the Trivers-Hare hypothesis. Evolution, 44, 1026-1034.

BoOmsma, J. J. AND GRAFEn, A. 1991. Colony-level sex ratio selection in the eusocial Hymenoptera. J. Evol. Biol., 3, 383-407.

BOURKE, A. F. G. AND FRANKS, N. R. 1995. Social Evolution in Ants. Princeton University Press, Princeton, NJ.

BRIAN, M. V. 1953. Oviposition by workers of the ant Myrmica. Physiol. Comp. Oecol., 3, 25-36.

BRIAN, M. V. 1969. Male production in the ant Myrmica rubra L. Insect Soc., 16, 249-268.

CHAPUISAT, M. 1996. Characterization of microsatellite loci in Formica lugubris B and their variability in other ant species. Mol. Ecol., 5, 599-601.

Elmes, G. w. 1991. The social biology of Myrmica ants. Actes Coll. Ins. Soc., 7, 17-34.

ElMES, G. W. AND Keller, L. 1993. Distribution and ecology of queen number in ants of the genus Myrmica. In: Keller, L. (ed.) Queen Number and Sociality in Insects, pp. 294-307. Oxford University Press, Oxford.

EVANS, J. D. 1993. Parentage analysis in ant colonies using simple sequence repeat loci. Mol. Ecol., 2, 393-397.

EVANS, J. D. 1996. Queen longevity, queen adoption, and posthumous indirect fitness in the facultatively polygynous ant Myrmica tahoensis. Behav. Ecol. Sociobiol., 39, 275-284.

GÖSSWALD, K. 1989. Die Waldameise. Band 1. AULAVerlag, Wiesbaden.

Gösswald, K. 1990. Die Waldameise. Band 2. AULAVerlag, Wiesbaden.

GRAFEN, A. 1991. Modelling in behavioural ecology. In: Krebs, J. R. and Davies, N. B. (eds) Behavioural Ecology - an Evolutionary Approach, 3rd edn, pp. 5-31. Blackwell Scientific Publications, Oxford.

HEINZE, J., PUCHINGER, W. AND HÖLlDOBLER, B. 1997. Worker reproduction and social hierarchies in Leptothorax ants. Anim. Behav., 54, 849-864.

MAMSCH, E. AND BIER, K. 1966. Das Verhalten von Ameisenarbeiterinnen gegenüber der Königin nach vorangegangener Weisellosigkeit. Insect Soc., 13, 277-284.

NONACS, P. 1992. Male parentage and sexual deception in the social Hymenoptera. In: Wrensch, D. L. and Ebbert, M. A. (eds) Evolution and Diversity of Sex Ratio in Insects and Mites, pp. 384-401. Chapman and Hall, New York.

PAMILO, P. 1982. Genetic population structure in polygynous Formica ants. Heredity, 48, 95-106.

PAMILO, P. 1985. Effect of inbreeding on genetic relatedness. Hereditas, 103, 195-200.

PAMILO, P. 1990a. Comparison of the relatedness estimators. Evolution, 44, 1378-1382.

PAMILO, P. 1990b. Sex allocation and queen-worker conflict in polygynous ants. Behav. Ecol. Sociobiol., 27, 31-36.

PAMILO, P. 1991a. Life-span of queens in the ant Formica 
exsecta. Insect Soc., 38, 111-120.

PAMILO, P. 1991b. Evolution of colony characteristics in social insects. II. Number of reproductive individuals. Am. Nat., 138, 412-433.

PAMILO, P. 1993. Polyandry and allele frequency differences between the sexes in the ant Formica aquilonia. Heredity, 70, 472-480.

PAMILO, P. AND ROSENGREN, R. 1983. Sex ratio strategies in Formica ants. Oikos, 40, 24-35.

QUELLER, D. C. AND GOODNIGHT, K. F. 1989. Estimating relatedness using genetic markers. Evolution, 43, 258-275.

RATNIEKS, F. L. W. 1988. Reproductive harmony via mutual policing by workers in eusocial Hymenoptera. Am. Nat., 132, 217-236.

Ross, K. G. 1993. The breeding system of the fire ant Solenopsis invicta: effects on colony genetic structure. Am. Nat., 141, 554-576.

SEPPÄ, P. 1994. Sociogenetic organization of Myrmica ruginodis and Myrmica lobicornis (Hymenoptera: Formicidae) colonies and populations: number, relatedness and longevity of reproducing individuals. J. Evol. Biol., 7, 71-95.

SEPPÄ, Р. 1996. Genetic relatedness and colony structure in polygynous Myrmica ants. Ecol. Ethol. Evol., 8, 279-290. SMEETON, L. 1981. The source of males in Myrmica rubra L. (Hym. Formicidae). Insect Soc., 28, 263-278.

SUNDSTRÖM, L. 1993. Genetic population structure and sociogenetic organization in Formica truncorum (Hymenoptera, Formicidae). Behav. Ecol. Sociobiol., 33, 345-354.

SUNDSTRÖM, L. 1994. Sex ratio bias, relatedness asymmetry and queen mating frequency in ants. Nature, 367, $266-268$.

SUNDSTRÖM, L. 1995. Sex allocation and colony maintenance in monogyne and polygyne colonies of Formica truncorum (Hymenoptera: Formicidae): the impact of kinship and mating structure. Am. Nat., 146, 182-201.

SUNDSTRÖM, L., CHAPUISAT, M. AND KELLER, L. 1996. Conditional manipulation of sex ratios by ant workers: a test for kin-selection theory. Science, 273, 993-995.

VARVIO-AHO, S. AND PAMILO, P. 1980. A new buffer system with wide applicability. Isozyme Bull., 13, 114.

\section{Appendix}

Numbers of individuals analysed per colony, markers, loci and the number of alleles studied, Enzyme Commission (EC) numbers and buffers used

\begin{tabular}{|c|c|c|c|c|c|c|}
\hline Enzyme/Locus & $E C$ & Buffer & F. exs. ${ }^{4}$ & F. trunc. & F. rufa & M. rug. \\
\hline$\alpha G p d h-1$ & 1.1.1.8 & I & & \multirow{3}{*}{2} & & 4 \\
\hline$\alpha G p d h-2$ & & & & & & \\
\hline$M d h$ & 1.1.1.37 & II & 2 & & & \\
\hline$I d h$ & 1.1.1.42 & II & & \multirow[t]{2}{*}{2} & & \\
\hline$P g d$ & 1.1.1.44 & II & & & 2 & \\
\hline$P g k$ & 2.7.2.3 & II & & \multirow[t]{3}{*}{2} & 2 & 2 \\
\hline Est ${ }^{1}$ & 3.1.1.1 & II & & & 2 & \\
\hline Est $-2^{1}$ & & & & & & 2 \\
\hline$P e p^{2}$ & $3.4 .^{*}{ }^{*}$ & & & \multirow{6}{*}{3} & 4 & 2 \\
\hline Aco & 4.2.1.3 & I & 2 & & & \\
\hline Pgm & 5.4.2.2 & II & 2 & & 3 & \\
\hline Microsatellite $^{3}$ & & & & & & \\
\hline FL21 & & & 25 & & & \\
\hline FL20 & & & 2 & & & \\
\hline \multirow[t]{2}{*}{ No. of individuals } & Workers & & 20 & $>30$ & 20 & 10 \\
\hline & Males & & $10-20$ & $>30$ & 20 & $3-20$ \\
\hline
\end{tabular}

Buffers: (I): Gel: $42.9 \mathrm{mmol} \mathrm{L}^{-1}$ Tris, $4.2 \mathrm{mmol} \mathrm{L}^{-1}$ citrate, $\mathrm{pH}$ 8.4; Tray: $135 \mathrm{mmol} \mathrm{L}^{-1}$ Tris, $42.9 \mathrm{mmol} \mathrm{L}^{-1}$ citrate, $\mathrm{pH} 7.1$ (Varvio-Aho \& Pamilo, 1980); (II): Gel: $9 \mathrm{mmol} \mathrm{L}^{-1}$ Tris, 3 mmol L ${ }^{-1}$ citrate, $1.2 \mathrm{mmol} \mathrm{L}^{-1}$ EDTA, pH 7; Tray:

$135 \mathrm{mmol} \mathrm{L}^{-1}$ Tris, $44.5 \mathrm{mmol} \mathrm{L}^{-1}$ citrate, $1.2 \mathrm{mmol} \mathrm{L}^{-1}$ EDTA, pH 7 (Ayala et al., 1974).

${ }^{1}$ 4-Methylumbelliferryl acetate as substrate.

${ }^{2}$ Glycyl-L-leucine as substrate.

${ }^{3}$ Chapuisat (1996).

${ }^{4}$ Sundström et al. (1996). 